\title{
The Development of Regulatory Foci Characters and Moderation Effects on Satisfaction and Commitment
}

\author{
Yannis Markovits \\ Alexander Technological Educational Institute of Thessaloniki, National Centre of Public Administration and Local Government, \\ Thessaloniki, Greece
}

\begin{abstract}
Regulatory Focus Theory is used to derive specific predictions regarding the differential relationships between regulatory focus and commitment. This study develops - for the first time - a conceptual framework based on Regulatory Focus Theory and its two underlying traits of promotion focus and prevention focus. This framework proposes four regulatory focus characters: "Achiever", "Conservative", "Rationalist" and "Indifferent". As well as constructing four distinguishable personality characters, it also proposes how these characters moderate the relationship between two prominent work-related attitudes: job satisfaction and organizational commitment; and in particular extrinsic satisfaction, normative commitment, and continuance commitment. Regression analyses and regression lines are constructed in order to examine the research hypotheses, in the private sector and public sector. The statistical analyses support the hypothesized relationships that regulatory focus moderates differently the relation between satisfaction and commitment according to the type of employment, i.e., there is a dual moderation: one based on self-regulation and another based on the economic sector. As far as, the development and examination of the four regulatory focus characters, only "Conservatives" exhib it a stronger relationship between extrinsic satis faction and continuance commit ment(for the private sector) and between extrinsic satisfaction and normative commitment(for the public sector). The paper concludes with a discussion of the managerial imp lications of this approach to regulatory focus, imp lications of these findings are discussed concerning the functioning of the regulatory foci characters, and suggestions for further research are proposed.
\end{abstract}

Keywords Regulatory Focus, Extrinsic Satisfaction, Normative Commitment, Continuance Commitment, Greece

\section{Introduction}

\subsection{Regulatory Focus and Job Satisfaction}

Examining the relevant literature review, the empirical research on regulatory focus tends not to focus on job satisfaction; and the key outcomes more commonly considered are goal attain ment(e.g., [4,9]), job performance(e.g., [25,26]) or individuals' emotions[2]. Two studies examined the direct relationship between regulatory focus and job sat is faction(e.g., [10,38]) and another study examined regulatory focus and job satisfaction with respect to transformational leadership, i.e., it examined the mediating role of transformational leadership on the regulatory focus-job satisfaction relationship[31]. The a forementioned studies concluded that when people are experiencing more positive emotions and circumstances at work than negative ones, then they are likely to be more satisfied with their jobs and tend to engage in organizational citizenship behaviors. In other words, the promotion focused individuals will be more satisfied with

* Corresponding author:

markovii@cyta.gr (Yannis Markovits)

Published online at http://journal.sapub.org/ijpbs

Copyright (C) 2012 Scientific \& Academic Publishing. All Rights Reserved their jobs than the prevention focused ones. However, by and large, these studies did not provide e mp irical evidence of any kind of relationship between regulatory focus and job satisfaction or dissatisfaction, apart from the study on the police officers[31], which also related regulatory focus with organizational change and organizational commitment[32]. Moreover, no study has been conducted on the relationship between the extrinsic facets of job satisfaction and the two aforementioned regulatory focus states. Since extrinsic satisfaction is derived from extrinsic rewards and according to Herzberg[8], the existence of this kind of rewards could make people feel non-dissatisfied with their jobs(the "hygiene factors" of a job), the prevention focused employees would seek primarily for the satisfaction of extrinsic factors of a job(e.g., wages, working conditions, personnel policies, security and safety, etc.), than the intrinsic factors. In short, prevention focused individuals could be more extrinsically satis fied fro $m$ their jobs than are the pro motion focused ones.

\subsection{Regulatory Focus and Organizational Commitment}

Searching in the relevant literature on regulatory focus and organizational commitment, it can be found that there are theoretical justifications for expect ing relationships between commitment and regulatory focus. Meyer, Becker, and Vandenberghe[21] presented a theoretical conceptualization 
arguing that individuals having a strong feeling of normative commit ment(i.e., emp loyees feeling obligated to remain with an organization) or continuance commit ment(i.e., employees assessing the costs associated with leaving an organization) may have a stronger prevention focus. Van-Dijk and Kluger[33] in their conceptual paper similarly argued that continuance commitment corresponds to prevention focus. However, the authors did not attempt to examine this relationship empirically. Moreover, Simo, Enache, Sallan Leyes, and Fernandez Alarcon[27] proposed, following a logical sequence of argument, that individuals with a high focus on prevention will display a higher level of vigilance to ensure safety and to avoid losses. They argued that continuance commitment, when prompted by prevention focused motivational framework, leads employees to fulfill only the minimu m work requirements, unlike that associated with an affective commitment motivational framework, in which an orientation towards promotion predominates, and will prompt individuals to act at their maximum performance levels. Although, this implication is conceptually logical, still its practical and empirical justification remained unproved.

Kark and Van-Dijk[13] presented a theory of how a chronic regulatory focus of leaders might affect their leadership style and the behavior of followers. Regarding the regulatory foci of the followers, they argued prevention-focused individuals are more influenced by external or social pressures and by the attempt to fulfill obligations and avoid losses. Thus, they are more likely to be committed to the organization out of a sense of obligation or necessity(normative or continuance commitment)"[13].

Moss, Ritossa and $\mathrm{Ngu[23]} \mathrm{examined} \mathrm{the} \mathrm{effect} \mathrm{of} \mathrm{fol-}$ lowers' regulatory focus and extraversion on leadership behavior, and found that followers' promotion focus moderated the relationship between corrective-avoidant behavior of the leader and subordinates' normative commitment. In other words, the researchers argued that when employees adopt a promotion focus, corrective-avoidant leadership is inversely related to normative commitment, and when they do not adopt promotion focus, corrective-avoidant leadership is positively related to this form of commitment. Their work did not investigate any direct re lationship between regulatory focus states and organizational commitment forms, but instead, developed moderating relationships among regulatory focus, organizational co mmitment, and leadership behaviors.

Recently, Johnson, Chang, and Yang[12] proposed the following relationships:(a) prevention foci contribute to the development of normative organizational commitment,(b) promotion foci contribute to the development of continuance organizational commitment(few alternatives), and(c) prevention foci contribute to the development of continuance organizational commitment(sacrificed investments). However, they acknowledged the lack of any substantial empirical evidence, except some preliminary evidence by Johnson and Chang[11]. They also found significant correlations between continuance commitment, both with promotion focus $(\mathrm{r}=.18)$ and prevention focus $(\mathrm{r}=.31)$. In gen- eral, there is some evidence from the relevant literature that the 'ought' form of commitment, i.e., normative commitment is fostered by prevention focus(e.g., [5,30]).

Finally, Markovits, Ullrich, Van Dick, and Davis[17] found - by using Structural Equation Modeling - that prevention focus is related more strongly to continuance commitment than promotion focus and promotion focus and prevention focus have equal strong effects on normative commitment. Moreover, Roundy[24] hypothesized and proved that employees with a promotion focus will have higher affective commitment during merges and acquisitions than employees with a prevention focus.

As it could be seen, from the presentation of the relevant literature, regulatory focus has been examined as a two-way relationship with respect to attitudinal variables. This study argues that moderation effects among regulatory foci, organizational commitment and job satisfaction could be exemplified, showing a more general and integrated picture on how this personality variable and principle of motivation that determines individuals' responses, i.e., the regulatory focus, moderates the satisfaction - commitment relationship. Moreover, this study, examines the role economic sector plays, arguing that the type of emp loyment(private or public sector employment) could moderate the aforementioned relationship. Finally, something unique in this research is the conceptual development of four distinguishable personality characters out of the two regulatory foci and their examination with in this moderation context.

\section{Objectives/Research Hypotheses}

\subsection{Extrinsic Satisfaction, Continuance Commi tment, and Regulatory Focus: The Private Sector}

In the private sector, emp loyees are faced with multiple or limited job opportunities and commitment to the organization has more relation to the job opportunities and/or the investments made by the individual. For example, Clugston[3] cited various empirical works showing that continuance commitment has a significant impact in the private sector for the turnover intentions and the job-related behaviors. Furthermore, Wasti[35] showed that in the private sector, endorsement of generalized norms for loyalty to one's organization, the in-group approval, and the informal recruitment would lead to higher levels of continuance commitment. Gill, Meyer, Lee, Shin, and Yoon[7] argued that continuance commitment was positively related to supervisors' ratings of deviant workplace behaviors in a sample of 120 private sector Korean workers and their supervisors, and through this result, they found a connection between non-preferred work behaviors and the more "negative" form of organizational commitment. Also, the perceived purpose in life as expressed through the two regulatory focus states - promotion(strong ideals) and prevention(strong oughts ) - related to the forms of commitment, e.g., prevention focused individuals are more committed to an organization out of necessity, than promotion focused ones[13]. 
This argument and taking under consideration the aforementioned findings, leads us to the development of the first research hypothes is.

Hypothesis 1: In the private sector the relationship between extrinsic and continuance commitment is moderated by promotion and prevention focus.

\subsection{Extrinsic Satisfaction, Nor mative Commitment, and Regulatory Focus: The Public Sector}

On the other hand, public sector employees place higher value on the normative aspects of commitment, i.e., the feelings of loyalty and obligation towards the organization they are working for, since public sector employment provides life-time and full-time security and a, more or less, a predetermined career development. Mintzberg[22] argued that control in the public sector is normative and it is the attitudes grounded in values and beliefs that matter, rather than the affective aspects of workp lace behaviors. Markovits, Davis, Fay, and Van Dick[16] proved that extrinsic satisfaction is mo re strongly re lated to normative commitment for the public sector employees than the private sector ones. Furthermore, Steijn and Leisink[29] showed that the Dutch civil servants have a distinct sense of obligation that comes out of the existence Public Sector Management(the 'call or sense of duty') influencing and strengthening the feeling of normative commitment. Also, in this case, employees being prevention focused exemplify their commitment as an obligation towards their organization or public service[13]. This line of argument leads us to the second research hypothesis.

Hypothes is 2: In the public sector the relations hip between extrinsic satisfaction and normative commitment is moderated by promotion and prevention focus.

\subsection{The Regulatory Focus Char acters}

Regulatory focus as a personality variable and a 'motivational' principle determines individuals' responses(through promotion and prevention focus mechanisms) to multiple stimuli and situations. Based on these two regulatory mechanis ms, employees develop four distinguishable personality characters based on the two regulatory foci; these could be named as "Achievers", "Conservatives", "Rationalists", and "Indifferent". The "Achiever" is the employee for whom promotion focus prevails and determines his or her decisions and behavior towards work and the organization. The "Conservative" is exactly the opposite: prevention focus prevails and guides decisions and work behavior. The third character, the "Rationalist" is the emp loyee who analyzes the costs and benefits of a work situation, measures and thoroughly examines the conditions and work assignments before he or she ultimately decides to accept or reject the risk or the job opportunity. In other words, the "Rationalist" exemplifies both promotion and prevention focus behaviors, depending on the specific circumstances and situations. The fourth character is the employee who does not want to be involved in any work assignment and prefers to remain isolated and indifferent from work and the o rganizat ion, overall.
The "Indifferent" is a person who is neither promotion focused nor prevention focused.

We propose that these characters intervene into the relationship between the two major organizational and job attitudes(organizational commitment and job satisfaction) by moderating the structure of this relationship. The recognition by management of these characters helps them to construct effective policies that could increase commitment and satisfaction of their employees. Furthermore, the substantial differences exhibited between private and public sector employees, provide further and demanding need to investigate how, and in what ways, regulatory focus characters moderate the relationship between commitment and satisfaction into these sectors of the economy. Based on the aforementioned conceptual analysis, figure 1 presents the conceptual framework of the research.

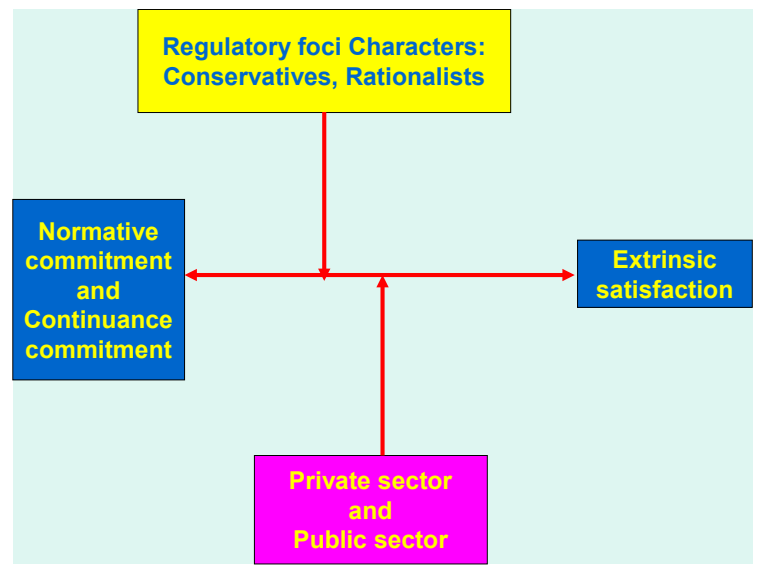

Figure 1. The conceptual framework

However, not all characters have the same effect on commitment and satisfaction, and the characters that dominate and have stronger intervention in this relationship are the "Rationalist"'(the emp loyees who measure and calculate the costs and benefits of their actions and the management policies exercised on them) and the "Conservative"(the employees who seek for security and safety in the working place - the prevention focused individuals). The reason for this proposition is that extrinsic satis faction deals mainly with the external rewards and satisfactions experienced by the employee and these two regulatory focus characters assess primarily the external, monetary and measurable results and benefits accrued from a job or an assignment. Thus, the research hypotheses based on these analys es are:

Hypothesis 3: In the private sector the relationship between extrinsic satisfaction and continuance commitment is stronger for "Rationalists" and "Conservatives" than any other regulatory focus character.

Hypothes is 4: In the public sector the relationship between extrinsic satisfaction and normative commitment is stronger for "Rationalists" and "Conservatives" than any other regulatory focus character.

\section{Methods}




\subsection{Me as ures}

The research hypothes es are tested via a quantitative study by using structured and previously published questionnaires. These scales are translated into Greek. Their use in other researches, especially those for job satisfaction and organizational commitment(e.g.,[15-18]), provided adequate guarantees of their good psychometric properties. The extrinsic satisfaction measure is based on the Minnesota Satis faction Questionnaire[39]. For continuance and normative commitment the Meyer, Allen, and Smith[20] scales have been used. The regulatory focus scale with its two constructs - promotion focus and prevention focus is taken from Lockwood, Jordan, and Kunda[14]. This scale has overall ten items, five for each regulatory focus state. The original scale comprises eighteen items, nine per regulatory focus, but four items from each state are omitted as they measure promotion focus and prevention focus states with respect to academic goals and performance. Also, positive affect and negative affect was measured via PANAS [37] as a control variable in order to see whether mood influences the expected relationships. The items are scored on a 7-point scale, having as endpoints $1=$ Complete disagreement, and $7=$ Complete agreement.

\subsection{Samples}

The samples are 258 employees from the private sector and 263 from the public sector, working in the Northern part of Greece. The sample is evenly split between private and public sector organizations and between male and female respondents. The private sector participants are drawn from thirty-three organizations, ranging from family owned small businesses to medium-sized industrial or commercial enterprises. The public sector respondents work in six governmental authorities (at a regional and local level) and tax and customs agencies in secure and primarily white-collar employment. The overall response rate is $67 \%$. The demographic characteristics of the sample are: $48.5 \%$ males and $51.5 \%$ females; mean age is 31 years; mean organizational tenure 7 years; of the total sample, about $84 \%$ of the sample is non-supervisory employees with approximately $16 \%$ heading functional departments of their organizations; the educational level is: $33.3 \%$ completed Secondary Education; $24.1 \%$ graduated fro m a Technological Educational Institute; $30.2 \%$ are University graduates; and $12.4 \%$ have a Postgraduate diploma.

\subsection{Descriptive, Correlation and Reliability Analyses}

The private sector sample(Table 1) presents strong positive inter-correlations between extrinsic satisfaction and normative commitment. Continuance commitment moderately correlates with extrinsic satisfaction and normative commitment. Prevention focus is weakly but positively correlated with continuance commitment, normative commitment, and negative affect. On the other hand, promotion focus is rather weakly correlated with extrinsic satisfaction, normative commitment, and mo re strongly to positive affect. This variable is negatively correlated with negative affect. Positive affect is positively correlated with all variables, apart from continuance commitment, and negative affect is negatively correlated with extrinsic satisfaction, as well as to positive affect. All variables have high reliability coefficients.

Table 1. Descriptive, Correlation and Reliability Analysis- Private Sector

\begin{tabular}{|c|c|c|c|c|c|c|c|c|c|}
\hline & $\alpha$ & Mean & St. dev. & ES & $\mathrm{CC}$ & $\mathrm{NC}$ & PA & NA & PREV \\
\hline ES & .87 & 4.72 & 1.07 & & & & & & \\
\hline $\mathrm{CC}$ & .71 & 4.50 & .95 & $.16^{* *}$ & & & & & \\
\hline $\mathrm{NC}$ & .82 & 4.31 & 1.35 & $.57^{* *}$ & $.36^{* *}$ & . & & & \\
\hline PA & .80 & 5.01 & .78 & $.34 * *$ & .00 & $.25 * *$ & & & \\
\hline NA & .80 & 2.85 & .79 & $-.18 * *$ & .00 & -.04 & $-.34 * *$ & & \\
\hline PREV & .70 & 4.31 & .92 & .08 & $.31^{* *}$ & $.29 * *$ & .07 & $.18^{*}$ & \\
\hline PROM & .72 & 5.52 & .76 & $.18^{* *}$ & .02 & $.14 *$ & $.47^{* *}$ & $-.27 * *$ & .07 \\
\hline
\end{tabular}

Notes: ** Correlation is significant at the 0.01 level(2-tailed). * Correlation is significant at the 0.05 level(2-tailed).

$\mathrm{ES}=$ Extrinsic satisfaction, $\mathrm{CC}=$ Continuance commitment, $\mathrm{NC}=$ Normative commitment, $\mathrm{PA}=$ Positive Affect, $\mathrm{NA}=\mathrm{Negative} \mathrm{Affect,} \mathrm{PREV}=\mathrm{Prevention}$ focus, $\mathrm{PROM}=$ Promotion focus

Table 2. Descriptive, Correlation and Reliability Analysis - Public Sector

\begin{tabular}{|c|c|c|c|c|c|c|c|c|c|}
\hline & $\alpha$ & Mean & St. dev. & ES & $\mathrm{CC}$ & $\mathrm{NC}$ & PA & NA & PREV \\
\hline$\overline{E S}$ & .77 & 4.72 & .84 & & & & & & \\
\hline $\mathrm{CC}$ & .80 & 4.65 & 1.17 & $.25^{* *}$ & & & & & \\
\hline NC & .84 & 4.29 & 1.20 & $.37 * *$ & $.24 * *$ & & & & \\
\hline PA & .90 & 4.88 & .97 & $.28 * *$ & $.18 * *$ & $47^{* *}$ & & & \\
\hline NA & .88 & 2.59 & .80 & $-.30 * *$ & $-.17 * *$ & $-.28 * *$ & $-.37 * *$ & & \\
\hline PREV & .72 & 4.52 & 1.02 & -.06 & $.22 * *$ & .03 & -.09 & .09 & \\
\hline PROM & .80 & 5.36 & .84 & $.29 * *$ & $.18^{* *}$ & $.41^{* *}$ & $.50 * *$ & $-.20^{* *}$ & -.08 \\
\hline
\end{tabular}

Note: ** Correlation is significant at the 0.01 level 
Table 3. Hierarchical Regression Analysis for Continuance Commitment, Extrinsic Satisfaction, and Regulatory Focus States - Private Sector

\begin{tabular}{|c|c|c|c|c|c|c|}
\hline & & & $\mathrm{CC}$ & & & \\
\hline & Step 1 & & Step 2 & & Step 3 & \\
\hline & $\mathrm{B}$ & SE b & $\mathrm{B}$ & SE b & $\mathrm{b}$ & SE b \\
\hline ES & $.18 * *$ & .06 & $.17 * *$ & .06 & $.16^{*}$ & .06 \\
\hline PROM & -.03 & .07 & -.04 & .07 & -.01 & .07 \\
\hline PREV & $.25 * *$ & .06 & $.26 * *$ & .06 & $.30 * *$ & .06 \\
\hline $\mathrm{PA}$ & -.07 & .07 & -.07 & .07 & -.07 & .07 \\
\hline NA & .00 & .06 & .02 & .06 & .03 & .06 \\
\hline Gender & .02 & .06 & .02 & .06 & .02 & .06 \\
\hline Age & .17 & .10 & .17 & .10 & .19 & .10 \\
\hline Educ. background & .03 & .061 & .02 & .06 & .02 & .06 \\
\hline Organ. hierarchy & .01 & .06 & -.01 & .07 & -.04 & .07 \\
\hline Year. service & -.12 & .10 & -.11 & .10 & -.10 & .09 \\
\hline ES * PROM & & & .07 & .05 & .05 & .05 \\
\hline ES * PREV & & & .07 & .06 & $.13 *$ & .06 \\
\hline PROM * PREV & & & $-.12 *$ & .06 & -.10 & .06 \\
\hline ES * PROM *PREV & & & & & $-.13 * *$ & .05 \\
\hline$\overline{\mathrm{R}^{2}}$ & .17 & & .19 & & .21 & \\
\hline Adjusted $\mathrm{R}^{2}$ & .12 & & .13 & & .16 & \\
\hline
\end{tabular}

Notes: $* * \mathrm{p}<.01, * \mathrm{p}<.05, \mathrm{~N}=258$

Table 4. Hierarchical Regression Analysis for Normative Commitment, Extrinsic Satisfaction, and Regulatory Focus States - Public Sector

\begin{tabular}{|c|c|c|c|c|c|c|}
\hline \multicolumn{7}{|c|}{$\mathrm{NC}$} \\
\hline & \multicolumn{2}{|l|}{ Step 1} & \multicolumn{2}{|l|}{ Step 1} & \multicolumn{2}{|l|}{ Step 3} \\
\hline & B & $\mathrm{SE} \mathrm{b}$ & $\mathrm{b}$ & $\mathrm{SE} \mathrm{b}$ & $\mathrm{B}$ & $\mathrm{SE} \mathrm{b}$ \\
\hline ES & $.28^{* *}$ & .07 & $.28 * *$ & .07 & $.29 * *$ & .07 \\
\hline PROM & $.22 * *$ & .07 & $.20 * *$ & .08 & .14 & .08 \\
\hline PREV & .12 & .06 & .12 & .07 & $.22 * *$ & .07 \\
\hline PA & $.36^{* *}$ & .08 & $.37 * *$ & .08 & $.43 * *$ & .08 \\
\hline NA & -.05 & .07 & -.05 & .08 & -.02 & .07 \\
\hline Gender & -.11 & .07 & -.10 & .07 & -.08 & .07 \\
\hline Age & .01 & .10 & .01 & .10 & -.01 & .10 \\
\hline Educ. background & -.10 & .07 & -.10 & .07 & -.09 & .07 \\
\hline Organ. hierarchy & .08 & .07 & .08 & .07 & .11 & .07 \\
\hline Year. service & .02 & .09 & .03 & .10 & .01 & .09 \\
\hline ES * PROM & & & -.06 & .07 & -.05 & .06 \\
\hline ES * PREV & & & .01 & .08 & .11 & .09 \\
\hline PROM * PREV & & & -.00 & .07 & -.04 & .07 \\
\hline ES * PROM *PREV & & & & & $-.23 * *$ & .07 \\
\hline $\mathrm{R}^{2}$ & .35 & & .35 & & .38 & \\
\hline Adjusted $\mathrm{R}^{2}$ & .32 & & .31 & & .34 & \\
\hline
\end{tabular}

Note: $* * \mathrm{p}<.01, \mathrm{~N}=263$

As far as the public sector sample is concerned(Table 2), extrinsic satis faction and the two organizational co mmitment forms are strongly positively correlated with each other. Positive affect is strongly correlated with all previous variables, as well as, to promotion focus, and negatively correlated with negative affect. On the other hand, negative affect is negatively correlated with extrinsic satisfaction, continuance and normative commitment, and promotion focus. Promotion focus is positively correlated with all previous variables; apart from negative affect(negative correlation). Finally, prevention focus is positively correlated with continuance commitment. The reliability coefficients are all high.

The results from the descriptive analyses especially that of the inter-correlations of the variables under examination, as well as, their reliability coeffic ients, lead us into the next step of the analysis, which is the hierarchical regression analyses of the variables, i.e., extrinsic satisfaction, normative commitment, continuance commitment, promotion focus, prevention focus, and the control variables(positive affect, negative affect, gender, age, educational background, orga- nizational hierarchy, and years of service in the organization).

\section{Results}

\subsection{Private Sector Sample}

Positive and negative affect, gender, age, educational background, organizational hierarchy, and years of service are the control variables in the regression analysis. All variables before they are entered into the regression analysis are $\mathrm{z}$-standardized. Table 3 presents the results from the regression analyses for continuance commitment, extrinsic satisfaction, and the regulatory focus states for the private sector sample; thus, verify ing hypothes is 1 . As it can be seen, the relationship between continuance commitment and extrinsic satisfaction is moderated by regulatory focus in the private sector. The three-way interaction is statistically significant at the 0.05 significance level and the $b$ coeffic ient is -0.13 for extrinsic satisfaction. The regression lines for this case are shown in Figure 2. Simple slopes for the relation- 
ships between extrinsic satisfaction and continuance commitment moderated by regulatory focus characters are significant for low promotion focus/high prevention focus "Conservatives" $(b=.33, t=3.10, p<.01)$ and for high promotion focus/high prevention focus - "Rationalists" $(\mathrm{b}=.22, \mathrm{t}$ $=2.61, \mathrm{p}<.01)$. "Conservative" employees become more continuance committed as they move from low to high levels of extrinsic satisfaction, than "Rationalists". This result is in line with hypothesis 3 since "Conservatives" and "Rationalists" are the only two regulatory focus characters that create significant relations between extrinsic satisfaction and continuance commitment.

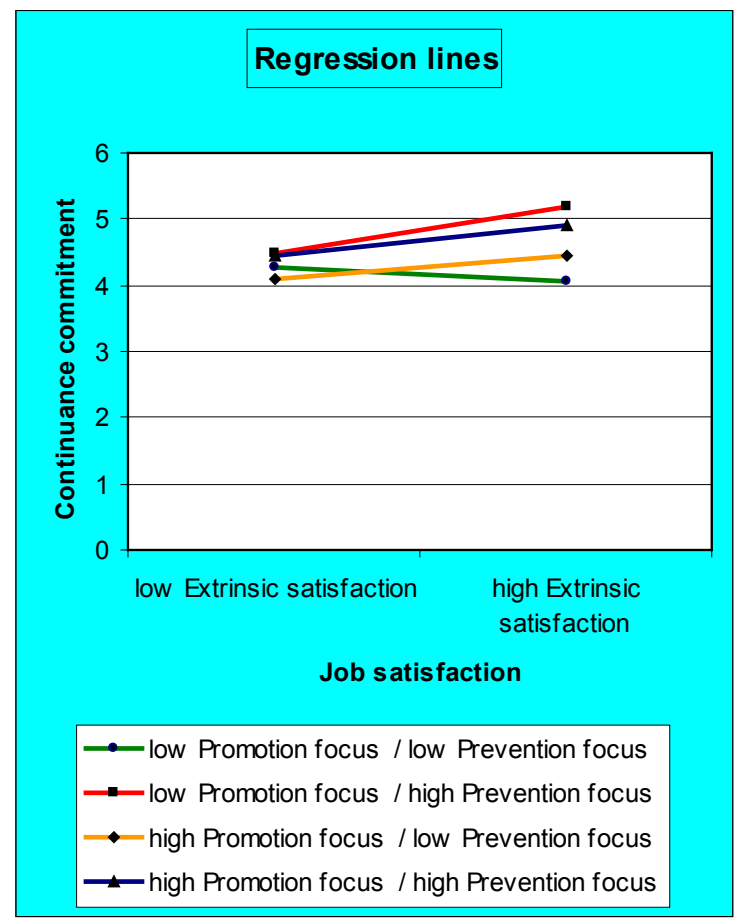

Figure 2. Regression lines for extrinsic satisfaction, continuance commitment and regulatory focus(private sector)

\subsection{Public Sector Sample}

Table 4 presents the results from the regression analyses for normative commitment, extrinsic satisfaction, and the regulatory focus states in the public sector. The relationship between normative commitment and extrinsic satisfaction is moderated by regulatory focus in this sector, providing support for hypothesis 2 . The three-way interaction is statistically significant at the 0.01 significance level and the $b$ coefficient is -0.23 for extrinsic satisfaction. The regression lines for this case are shown in Figure 3. Simple slopes for extrinsic satisfaction predicting normative commitment are significant for high promotion focus/low prevention focus "Achievers" $(\mathrm{b}=.31, \mathrm{t}=2.84, \mathrm{p}<.01)$ and for low promotion focus/high prevention focus - "Conservatives" $(b=.59$, $\mathrm{t}=4.89, \mathrm{p}<.01$ ). "Conservative" employees become more normatively committed as they move from low to high levels of extrinsic satisfaction, than "Achievers". This result partially supports hypothesis 4, since only "Conservatives" manage to produce significant results and not "Rationalists".

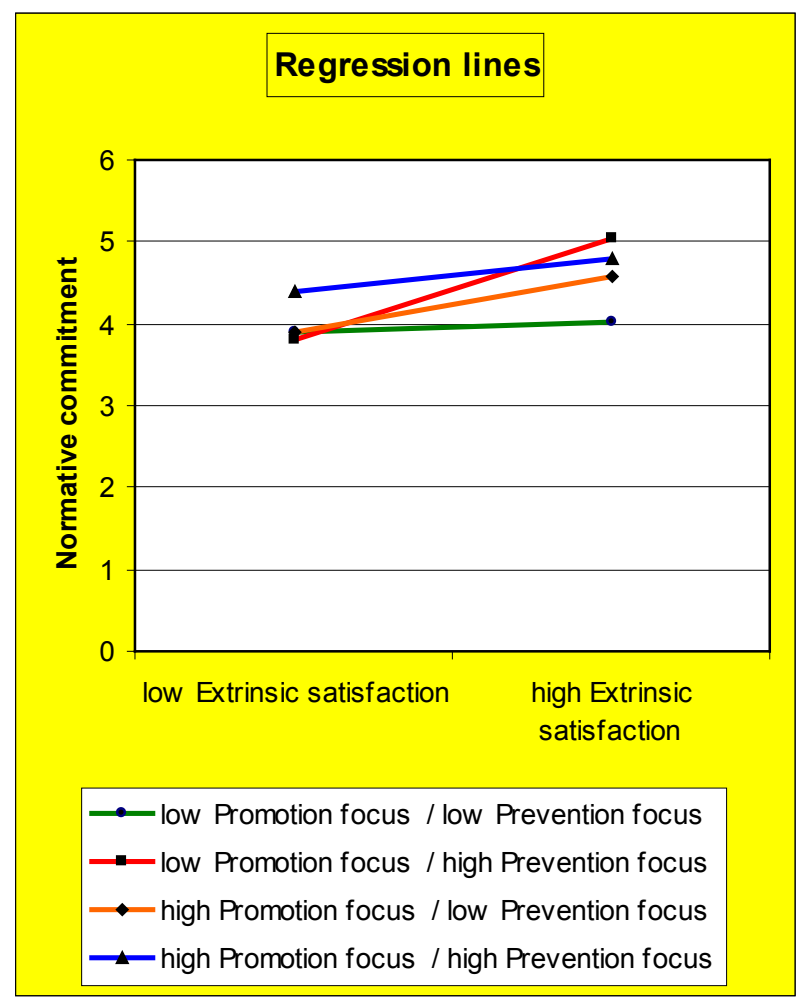

Figure 3. Regression lines for extrinsic satisfaction, normative commitment and regulatory focus(public sector)

\section{Discussion}

As it can be seen from the tables of the hierarchical regression analyses and the figures with the regression lines, the first two research hypotheses proved to be true and in the private sector, the extrinsic satisfaction/continuance commitment relationship is moderated by promotion focus and prevention focus. As far as the public sector is concerned, the regulatory focus states moderate the extrinsic satisfaction/normative commitment relationship. The moderation effect addresses 'when' or 'for whom' a predictor variable continuance and normative commitment in this case - is more strongly related to an outcome variable - extrinsic satisfaction[6]. In other words, the relationship between the two forms of commitment and extrinsic satisfaction is stronger when regulatory focus has high scores. It seems that employees feel more confident to assess their extrinsic components of satisfaction, which are more evident, than to relate their satisfaction with the job they do, with respect to opportunities provided by management, or recognition and support given by supervisors.

Turning to the regulatory focus characters, the results are mixed. Regarding the hypothesis supporting that in the private sector the extrinsic satisfaction/continuance commitment relationship is stronger for "Rationalists" (high promotion focus/high prevention focus) and for "Conservatives"(low promotion focus/high prevention focus, than the other two regulatory focus characters, it was statistically supported. It has been also hypothesized that in the public 
sector the extrinsic satis faction/normative commitment relationship will be stronger for "Rationalists" and "Conservatives" than any other regulatory focus character; however, only "Conservatives" managed to produce statistically significant results and not "Rationalists". This result could be explained due to the nature of the employment relationship in the public sector and the bureaucratic and hierarchical system of its organization. "Rationalists" in the public sector may express different dispositions than "Rationalists" in the private sector, or the situational factors could influence the final relationship between the attitudes. However, it is important to point out that the effect of dispositions and situational factors on this moderating relationship is still unclear, and by and large, undisclosed. Further studies need to be conducted, both confirmatory and qualitative. Moreover, probably another scale for the measurement of regulatory focus has to be used that will be more work-focused.

\section{Conclusions}

The results show that regulatory focus moderates differently the relation between satisfaction and commitment according to the type of employment. In other words, there can be a dual moderation: one based on self-regulation and another based on the economic sector. This finding should be important for the HRM practitioners and managers in the private and public sector alike. On the other hand, the results obtained from the examination of the regulatory focus characters should be interpreted with caution. It seems that only "Conservatives" exhibit a stronger relationship between extrinsic satisfaction and continuance commitment(for the private sector) and between extrinsic satisfaction and normative commitment(for the public sector) showing that employees who tend to behave by safeguarding their interests and their current job positions and status, are the ones that significantly positively relate satisfaction to commitment. There are also indications that "Rationalis ts" exe mp lify these sorts of relationship; however, these have not been proved to exist for all types of emp loyees.

The implication for OB theory is important for two main reasons: firstly, the type of regulation is directly related to satisfaction/commitment, so that employees' personality characteristics influence their attitudinal relationships. The knowledge of regulatory processes and the distinction of employees between promotion focused and prevention focused moderates the relation between satisfaction and commitment. Moreover, this relation is further influenced by the type of emp loyment. Secondly, it is the construction - for the first time - of particular and distinguishable regulatory focus characters, extending the broad division between promotion and prevention focus to four characters. The construction of the four separable characters widens the differentiation of personality characteristics based on self-regulation and provides a more detailed and thorough model on the relationship between self-regulation and em- ployee attitudes. However, this model needs further investigation and cross-validation.

The inclusion of regulatory focus in the model showed that promotion focus and prevention focus moderate the extrinsic satisfaction/continuance commitment relationship in the private sector and the extrinsic satisfaction/normative commitment relationship in the public sector. This finding is important for management practitioners, since it strengthens the argument that HRM policies should be more personalized and psychology-driven, because human beings are complex organisms and have different personality characteristics and behavioral patterns. Moreover, the results from the statistical analyses showed that in the private sector, individuals are primarily characterized as prevention focused("Conservatives") and individuals exemplify ing both regulatory focus states("Rationalists") tend to be more continuance committed as they move from low to high values of extrinsic satisfaction with their job. "Rationalists" in particular, are also likely to appreciate this recognition of commitment and would be willing to "go the extra mile" for a valued employer, generating greater possibility for extrinsic rewards. The attention and concern for a work environment which meets their idealistic aspirations in pursuit of their personal values may also incorporate expectations of high levels of extrinsic reward. "Rationalists" have both a greater concern for personal security and a strong sens e of obligation, and this is recognized and reflected in their higher levels of continuance and normative commitment. On the other hand "Conservatives", who share these concerns, do not internalize the contribution of the organization. These outcomes are valuable for HR managers, since it acknowledges the fact that employees rationalize management policies and assess the costs and benefits of their decisions, having always in their mind the safeguarding of their current status and employment position. More or less, this is the lesson learnt from the public sector, but in this case, the safeguarding affects the increase on normative commitment as employees move from low to high values of ext rins ic satis faction.

The imp lications for HRM specialis ts and practitioners are significant, given the associations between regulatory focus and these two core job-related attitudes. For "Achievers", with their focus on pursuit of their own ideals, flexibility and the availability of intrinsic reward could be most effective in enhancing performance. Micro-management and target setting are likely to be met with voluntary resignations, although linking the availability of rewards to the success ful completion of tasks, which "Achievers" find stimulating and worthwhile, could be effective in generating higher levels of performance, although probably not any greater sense of loyalty for the organization. "Conservatives" are likely to be good 'company men'. They tend to be reliable and to an extent predictable, although they may not respond positively to organizational change due to a prevention focused stance to life and work. Highly contingent reward packages where individual responsibilities are ill-defined or difficult to measure could also be unpopular among "Conservatives". 
On the positive side, it could be argued that they would perform well as long as they feel their rewards are fair, and may well be good organizational citizens. "Indifferents" may at first sight appear to be the type of employee best avoided. This is not entirely accurate. It seems that an organization consisting of only the three other characters would become unstable as the personal and calculative interpretations of the emp loyees could pull the company apart. For "Indifferents", work seems to be simply not that central and therefore they tend to bring a balance to what might otherwise become a highly strung environment. They may be the cool head through which change is considered without the personal or organizational vested interests of the "Achievers" or the "Conservatives". While they may not be the most dynamic or challenging group of employees, they probably do what is required; however, further investigation needs in order to confirm this assertion. Finally, "Rationalists" seem to live and breathe their organization. Their attachment to the organization coupled with the striving characteristic of a promotion focus would make them good long-term investments. However, this attachment needs to be reciprocated by providing a secure and safe workplace and an employment contract which demonstrates commitment on the part of the emp loyer. While "Achievers" may drive change, "Rationalists" will make it happen, both through their own actions and through convincing "Conservatives" and motivating "Indifferents". "Rationalists" could be characterized as the "cool mind' of the emp loyees of an organization, since they tend to rationalize their actions and motives through the evaluation of costs and benefits of management policies and in itiatives. Overall, the knowledge of the existence of these four regulatory focus characters could provide an immense help to managers in order to develop appropriate HRM and Organizational Development(OD) policies and practices which accommodate these characters. However, it should be pointed that the aim of the current study was not to interpret the four regulatory focus characters with respect to employees' behavior at work and management actions, but to develop these characters per se and see how they are related to the job-related attitudes. Further research needs to be conducted, primarily of qualitative nature, where emp loyees could be asked to evaluate their feelings and show their responses towards management policies and actions, based on these four regulatory focus characters.

Moreover, the results from the relationship between regulatory foci and the forms of organizational commitment point out the important role that regulatory focus may play in affecting the different components of commitment. This could have practical implications for personnel selection, development, and leadership. Depending on the nature of work, organizations may be inclined predominantly to select promotion or prevention focused employees. However, they may not anticipate the potential consequences such a selection strategy may have for the resulting commitment profiles(see $[18,36]$ ). Likewise, these results may be useful for personnel development and leadership in that, different regulatory foci could be made salient with predictable conse- quences for organizational commitment.

\subsection{Limitations}

An important limitation of this study is the problem with the common-variance method that arises fro $m$ self-report and mono-source methodological tools adopted. This method biases are attributable to the measurement method, rather than to the construct of interest[1]. This might account for some inflation of the relationships between the variables used for the research, but apparently cannot be responsible for finding links. However, there are relatively few alternatives to this type of field studies. This deficiency is exhibited in all field studies using self-reported quantitative-type questionnaires. It is difficult to envisage a way in which individual attitudes such as job satisfaction can be assessed other than through self report. This is less of a problem, however, for the hypothesized interaction effects. The problem of common method variance cannot account for interactions among variables but leads to an underestimation of these statistical interactions[19]. Despite the mono-source design, there should be confidence in the interactions obtained. Moreover, the instruments developed for this research have well proven psychometric properties, suggesting that they are likely to be resistant to common method variance[28].

One alternative to overcome this limitation might be to focus on a more qualitative approach, although personal interviews with a s mall number of respondents would limit generalizability. Longitudinal studies incorporating behavioral data from third party informants are strongly advocated in the literature. However such an approach was not possible here and third party informants would be unable to comment on individual attitudes. Third party reports of satisfaction or behavioral assessment of commitment are clearly avenues to be pursued in future. However, given that the main contribution of this research was the development and examination of a conceptual framework incorporating attitudes, self-regulations, and economic sectors, these further lines of research remain to be developed.

Another limitation is the Greek translation of items, initially constructed in English or of an English-speaking audience. Thus, interpretation problems could be arise, thus, some statements were further explained when written in Greek This research decided to direct translate the items assuming to be 'etic', instead of adopting the belief that quantitative researches should use culturally appropriate 'emic' measures([16,34]). Finally, the samples are convenient ones, thus, this may limit the generalizability of the findings, although the relatively large sample sizes mediated this shortcoming. The sample sizes were large enough, providing acceptable statistical power to the results. However, the inclusion of a selection of relevant control variables, both demographic and attitudinal(positive and negative affectivity), seeks to limit the extent to which individual experience might confound the outcomes.

Finally, future work should aim at testing the stability and generalizability of the differential relationships between the 
moderating role of regulatory focus on the satisfaction/commitment relationship, or the differential relationships between regulatory foci and components of commitment, that were all observed during this research.

\subsection{Recommendations for Future Research}

The moderating role of regulatory focus to the satisfaction/commitment relationship needs to be further tested on the stability and generalizability of its conceptual fra me work. Clearly some of the hypotheses generated regarding behavioral outcomes of these regulatory focus characters are directly testable and will be the subject of future research. In particular, the present empirical study needs further rep lication in other cultural contexts, either as part of a longitudinal study in the same cultural context, or as a cross-cultural and a cross-national study. A future study needs also to research/examine the four regulatory focus characters and re-confirm their typological nature, and not simply their dimensional one. Moreover, this framework could be extended and related more closely to Self-Determination Theory, thus generating a more general model for the motivational and attitudinal processes within organizations. Qualitative study of the more personalized and specific areas of regulatory focus and organizational and job attitudes may also prove illuminating. This can be further connected to qualitative material selected by managerial assessments of employees' self-regulation and attitudes towards their job and organization.

\section{REFERENCES}

[1] Bagozzi, Richard P., Yi, YouJae, "Multitrait-multimethod matrices in consumer research", Journal of Consumer Research, Chicago Journals, vol. 17, March, pp. 426-439, 1991.

[2] Brockner, Joel, Higgins, E.Tory., "Regulatory focus theory: Implications for the study of emotions at work", Organizational Behavior and Human Decision Processes, Elsevier, vol. 86 , issue 1, pp. 35-66, 2001.

[3] Clugston, Michael, "The mediating effects of multidimensional commitment on job satisfaction and intent to leave", Journal of Organizational Behavior, Wiley, vol. 21, issue 4, pp. 477-486, 2000.

[4] Förster, Joel, Higgins E. Tory, and Idson, Loraine Chen, "Approach and avoidance strength during goal attainment: Regulatory focus and the 'goal looms larger' effect", Journal of Personality and So cial Psy chology, APA Inc., vol. 75, no. 5, pp. 1115-1131, 1998.

[5] Frank, Elizabeth, Brandstätter, Veronika, "Approach versus avoidance: Different types of commitment in intimate relationships", Journal of Personality and Social Psychology, APA Inc., vol. 82, no. 2, pp. 208-221, 2002.

[6] Frazier, Patricia A., Tix, Andrew P., and Barron, Kenneth E., "Testing moderator and mediator effects in counseling psychology and research", Journal of Counseling Psychology, APA Inc., vol. 51, no.1, pp. 115-134, 2004.
[7] Gill, Harjinder, Meyer, John P., Lee, Kibeom, Shin, Kang-Hyun, and Yoon, Chang-Young, "Affective and continuance commitment and their relations to deviant workplace behaviors in Korea", Asia Pacific Journal of Management, Springer, vol. 28, no. 3, pp. 595-607, 2011.

[8] Herzberg, Frederick, "One more time: How do you motivate employees?", Harvard Business Review, Harvard University, vol. 46, pp. 53-62, 1968.

[9] Higgins, E. Tory, Shah, James, and Friedman, Ronald S., "Emotional responses to goal attainment: Strength of regulatory focus as moderator", Journal of Personality and Social Psychology, APA Inc., vol. 72, no. 3, pp. 515-525, 1997.

[10] Higgins, E. Tory, Simon, Michael, and Wells, Richard S., A model of evaluative processes and 'job satisfaction': When differences in standards make a difference, In R. Cardy, J. Newman and S.M. Puffer(eds.) "Advances in information processing in organizations", vol. 3, Greenwich, CT: JAI Press, pp. 81-105, 1998.

[11] Johnson, Russell E., Chang, Chu-Hsiang, "I' is to continue and 'we' is to affective: The relevance of the self-concept to organizational commitment", Journal of Organizational Behavior, Wiley, vol. 27, no. 5, pp. 549-570, 2006.

[12] Johnson, Russell E., Chang, Chu-Hsiang, and Yang. Liu-Quin, "Commitment and motivation at work: The relevance of employee identity and regulatory focus", Academy of Management Review, AOM, vol. 35, no. 2, pp. 226-245, 2010.

[13] Kark, Ronit, Van-Dijk, Dina, "Motivation to lead, motivation to follow: The role of the self-regulatory focus in leadership processes", Academy of Management Review, AOM, vol. 32, no. 2, pp. 500-528, 2007.

[14] Lockwood, Penelope Jordan, Christian H., and Kunda, Ziva, "Motivation by positive or negative role models: Regulatory focus determines who will best inspire us", Journal of Personality and Social Psychology, APA Inc., vol. 83, no. 4, pp. 854-864, 2002.

[15] Markovits, Yannis, "Normative commitment and loyal boosterism: Does job satisfaction mediate this relationship?", MIBES Transactions, TEI Larissas, vol. 5, issue 1, pp. 73-89, 2011.

[16] Markovits, Yannis, Davis, Ann J., Fay, Doris, and Van Dick, Rolf, "The link between job satisfaction and organizational commitment: Differences between public and private sector employees", International Public Management Journal, Taylor \& Francis, vol. 13, issue 2, pp. 177-196, 2010.

[17] Markovits, Yannis, Ullrich, Johannes, Van Dick, Rolf, and Davis, Ann J., "Regulatory foci and organizational commitment", Journal of Vocational Behavior, Elsevier, vol. 73, no. 3, pp. 485-489, 2008.

[18] Markovits, Yannis, Davis, Ann J., and Van Dick, Rolf, "Organizational commitment profiles and job satisfaction among Greek private and public sector employees", International Journal of Cross-Cultural Management, Sage Journals, vol. 7, no. 1, pp. 77-99, 2007.

[19] McClelland, Gary H., Judd, Charles M., "Statistical difficulties of detecting interactions and moderator effects", Psychological Bulletin, APA Inc., vol. 114, no. 2, pp. 376-390, 1993.

[20] Meyer, John P., Allen, Natalie J., and Smith, Catherine A., 
"Commitment to organizations and occupations: Extension and test of a three-component conceptualization", Journal of Applied Psychology, APA Inc., vol. 78, no. 4, pp. 538-551, 1993.

[21] Meyer, John P., Becker, Thomas E., and Vandenberghe, Christian, "Employee commitment and motivation: A conceptual analysis and integrative model", Journal of Applied Psychology, APA Inc., vol. 89, no. 6, pp. 991-1007, 2004.

[22] Mintzberg, Henry, "Managing government governing management", Harvard Business Review, Harvard University, May/June, pp. 75-83, 1996.

[23] Moss, Simon, Ritossa, Damian, and N gu, Simon, "The effect of follower regulatory focus and extraversion on leadership behavior", Journal of Individual Differences, APA Inc., vol. 27, no. 2, pp. 93-107, 2006.

[24] Roundy, Philip, T. "Can stories breed commitment? The influence of mergers and acquisitions narratives on employees regulatory focus", Institute of Behavioral and Applied Management, University of Texas at Austin, 2010.

[25] Shah, James, Higgins, E. Tory, "Regulatory concerns and appraisal efficiency: The general impact of promotion and prevention", Journal of Personality and Social Psychology, APA Inc., vol. 80, no. 5, pp. 693-705, 2001.

[26] Shah, James, Higgins, E. Tory, and Friedman, Ronald S., "Performance incentives and means: How regulatory focus influences goal attainment", Journal of Personality and Social Psychology, APA Inc., vol. 74, no. 2, pp. 285-293, 1998.

[27] Simo, Pep, Enache, Michaela, Sallan Leyes, Jose-Maria, and Fernandez Alarcon, Vincenc, "Analysis of the relation between subjective career success, or ganizational commitment, and the intention to leave the organization", Transylvanian Review of Administrative Sciences, AP Publishers, vol. 29, no. E, pp. 144-158, 2010.

[28] Spector, Paul E., "Method variance as an artefact in self-reported affect and perceptions at work: Myth or significant problem?", Journal of Applied Psychology, APA Inc., vol. 72, no. 3, pp. 438-443, 1987.

[29] Steijn, Bram, Leisink, Peter, "Organizational commitment among Dutch public sector employees", International Review of Administrative Sciences, Sage Journals, vol. 72, no. 2, pp. 187-201, 2006.

[30] Strachman, Amy, Gable, Shelly L., "Approach and avoidance relationship commitment", Motivation and Emotion, Springer Science+Business Media Inc., vol. 30, issue 2, pp. 117-126, 2006.

[31] Tseng, Hsing-Chau., Kang, Long-Min, "Regulatory focus, transformational leadership, uncertainty towards organizational change, and job satisfaction: In a Taiwan's cultural setting", Asia Pacific Management Review, TSCCI, vol. 14, no. 2, 215-235, 2009.

[32] Tseng, Hsing-Chau, Kang, Long-Min, "How does regulatory focus affect uncertainty towards organizational change?", Leadership \& Organization Development Journal, Emerald, vol. 29, issue 8, pp.713-731, 2008.

[33] Van-Dijk, Dina, Kluger, Avraham N., "Feedback sign effect on motivation: Is it moderated by regulatory focus?", Applied Psy chology: An International Review, Wiley, vol. 53, no. 1, pp. 113-135, 2004.

[34] Vandenberghe, Christian, "Application of the three- component model to China: Issues and perspectives", Journal of Vocational Behavior, Elsevier, vol. 62, no. 3, pp. 516-523, 2003.

[35] Wasti, S. Arzu, "Affective and continuance commitment to the organization: Test of an integrated model in the Turkish context", International Journal of Intercultural Relations, Elsevier, vol. 26, issue 5, pp. 525-550, 2002.

[36] Wasti, S. Arzu, "Commitment profiles: Combinations of organizational commitment forms and job outcomes", Journal of Vocational Behavior, Elsevier, vol. 67, no. 2, pp. 290-308, 2005.

[37] Watson, David, Clark, Lee A., and Tellegen, Auke, "Development and validation of brief measures of positive and negative affect: The PANAS scales", Journal of Personality and Social Psychology, APA Inc., vol. 54, no. 6, pp. 1063-1070, 1988.

[38] Weiss, Howard, Cropanzano, Russell, Affects events theory: A theoretical discussion of the structure, causes and consequences of affective experien ces at work, In B.M. Staw, L.L. Cummings(eds.) "Research in organizational behavior", vol. 18, Greenwich, CT: JA Press, USA, pp. 1-74, 1996.

[39] Weiss, David J., Dawis, Rene V., England, George W., and Lofquist, Lloyd H., "Manual for the Minnesota Satisfaction Questionnaire", Minnesota Studies in Vocational Rehabilitation Bulletin, Minnesota University, no. 22, 1967. 